\title{
Herencia, adaptación y evolución: nuevas propuestas teóricas y su aporte a la Teoría de los Sistemas de Desarrollo
}

\author{
Heredity, Adaptation and Evolution: New Theoretical Proposals and \\ their Contribution to the Developmental Systems Theory
}

D.0.I.: https://doi.org/10.30550/j.azl/2018.62.2/7

\begin{abstract}
Agustina Domínguez
Cátedra de Lógica y Metodología de la Ciencia, Facultad de Ciencias Naturales y Museo (Universidad Nacional de La Plata), Avenida 122 y 60, CP 1900, La Plata, Buenos Aires, Argentina.

agustinadomz@gmail.com
\end{abstract}

\begin{abstract}
- Resumen - Las ciencias biológicas se encuentran bajo el paradigma de la Teoría Sintética de la Evolución (TSE), cuyos fundamentos teóricos y epistémicos empiezan a mostrar debilidad producto del avance de distintos campos y la acumulación de evidencia empírica que no se explica bajo los supuestos de dicha teoría. La Teoría de los Sistemas de Desarrollo (TSD) es una perspectiva teórica inclusiva de la biología del desarrollo, la herencia y la evolución que propone una superación de la dicotomía entre caracteres innatos y adquiridos. Disciplinas tales como la epigenética, las ciencias del comportamiento y otras teorías como la Teoría de Construcción de Nicho (TCN) aportan a la misma a través de la integración de diversos factores para entender los procesos biológicos. En el presente trabajo se analiza evidencia experimental y propuestas teóricas de varios autores que permiten definir conceptos tales como evolución, adaptación y herencia de una manera más amplia. Estos temas, aunque desconsiderados por la mayoría de los autores dentro del campo de la biología como mera filosofía, constituyen marcos teóricos que delimitan y guían los problemas y preguntas en investigación por lo que abordarlos resulta un intento decisivo para reflexionar sobre los paradigmas actuales. Se concluye la necesidad de cuestionar y redefinir los conceptos fundamentales y su articulación con las teorías que los contienen con el fin de lograr una mayor capacidad explicativa de los procesos evolutivos.
\end{abstract}

Palabras clave: Biología teórica, comportamiento, epigenética.

- Abstract - Biological sciences are under the paradigm of the Synthetic Theory of EvoIution [STE]. The theoretical and epistemological basis of it is starting to show weakness as a result of the progress made by other fields and the accumulation of empiric evidence that cannot be explained under its assumptions. The Developmental Systems Theory (DST) is a theoretical inclusive proposal for heredity, evolution and developmental biology. Fields such as epigenetics, behavioural sciences and other theories such as Niche Construction Theory (NCT) contribute to DST by the integration of diverse factors so to understand biological processes. In the present research we analyze evidence from epigenetics, behavioural sciences and theoretical proposals from diverse authors that allow understanding of concepts as evolution,

\footnotetext{
> Ref. bibliográfica: Domínguez, A. 2018. Herencia, adaptación y evolución: nuevas propuestas teóricas y su aporte a la Teoría de los Sistemas de Desarrollo. Acta zoológica lilloana 62 (2): 57-69.

> Recibido: 17/08/18 - Aceptado: 09/11/18

$>$ URL de la revista: http://actazoologica.lillo.org.ar

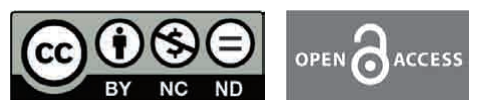

$>$ Algunos derechos reservados. Esta obra está bajo una Licencia Creative Commons Atribución - No Comercial - Sin Obra Derivada 4.0 Internacional.
} 
inheritance and adaptation in a broader manner. These topics, although are seen within the biology field as mere philosophy by most authors, constitute theoretical frames that restrict and guide problems and questions in research and that is why addressing them results in an attempt to think about current paradigms. It is concluded the necessity to question and redefine the fundamental theoretical concepts and its articulation with the theories that contain them in order to get a bigger explanatory power about evolutionary processes.

Keywords: Theoretical biology, behaviour, epigenetics.

\section{INTRODUCCIÓN}

En las ciencias biológicas, el paradigma dominante es la Teoría Sintética de la Evolución (TSE), que data de mediados del siglo XX, cuando se unificaron tres campos disciplinares: la genética de poblaciones, la paleontología y la sistemática, con sus respectivos principios teóricos, en un intento de entender cómo ocurría la evolución (Dobzhansky, Ayala, Stebbins y Valentine, 1977). En esta teoría, el gen tiene un papel preponderante en la especiación como portador de información para el desarrollo y agente de variación poblacional. Sin embargo, su definición ha ido cambiando a lo largo de los años desde principios del siglo pasado (Dressino, 2010). Este paradigma se encuentra en crisis ya que existen contradicciones lógicas, epistémicas y teóricas, producto del avance de distintas disciplinas y la acumulación de evidencia empírica que la TSE no alcanza a explicar (Dressino, 2010).

A partir del desarrollo de la epigenética y de la investigación asociada a otros tipos de herencia no genética (conocida como 'soft inheritance' — herencia suave-), además de otras propuestas teóricas como la construcción de nicho (Odling Smee, 1996; ScottPhillips, Laland, Shuker, Dickins, y West, 2014) se ha instalado un paradigma nuevo a favor de modelos de desarrollo y evolución más holísticos (Jablonka y Lamb, 2005). La Teoría de los Sistemas de Desarrollo (TDS) propone una superación de la dicotomía entre caracteres innatos y adquiridos donde los aspectos genéticos y ambientales son claves para comprender los modelos de desarrollo y evolución. El entendimiento del desarrollo como un sistema dinámico, en el cual el proceso construye al individuo y a la vez al entorno (tanto físico como social), lleva- ría a reformular ciertos términos teóricos y, eventualmente, a evaluar si están en concordancia con la teoría dominante. En el presente trabajo se revisan nuevas propuestas teóricas sobre biología del desarrollo desde la perspectiva de la TSD, con la finalidad de establecer sus implicancias en términos de herencia, adaptación y evolución.

\section{LA TEORÍA DE LOS SISTEMAS DE DESARROLLO}

La Teoría de los Sistemas de Desarrollo (TSD) es una perspectiva teórica inclusiva de la biología del desarrollo, la herencia y la evolución. Desarrollada por Susan Oyama en su libro «La ontogenia de la información: sistemas de desarrollo y evolución», fue publicada originalmente en 1985. Allí, se propone que la dicotomía entre lo innato (presente como información encriptada en los genes) y lo adquirido (experiencias con el ambiente externo al organismo) es un supuesto erróneo. Este enfoque procede de una larga tradición filosófica enmarcada dentro de nuestra forma de abordar y entendernos tanto a nosotros mismos como a los demás organismos y al mundo:

«La creencia en la forma y el destino genético parecen enraizadas en nuestro deseo de derivar de la ciencia las respuestas a preguntas muy antiguas sobre qué somos, nuestro propósito y lo que podemos llegar a ser» (Oyama, 2000, p. 8).

En Occidente, el entendimiento del origen de la vida y su desarrollo vienen dados por una dicotomía entre forma y materia (natura-nurtura) y la idea preformacionista sobre la esencia o la forma de los seres vivos. Estas ideas datan del Génesis, continúan presentes en la filosofía griega Aristotélica y más tarde 
en concepciones Newtonianas y Cartesianas. A lo largo de la historia se ha desarrollado la creencia que la materia es inerte y que los organismos, como objetos materiales, requieren de una animación externa. Esta animación fue concebida de diversos modos, por ejemplo, como el otorgamiento de una 'forma' proveniente de Dios o de una fuerza vitalista. Esto se encuentra reflejado en la producción de diversos pensadores:

«Esta separación entre forma y materia subyace y une todas las versiones de la antítesis natura-nurtura que tan persistentemente han fundado nuestros abordajes filosóficos y científicos sobre el fenómeno de la vida» (Oyama, 2000, p. 1).

El método y la forma a través de los cuales se impondría la forma a la materia han ido variando a lo largo del tiempo. Actualmente, el paradigma dominante establece que son los genes los garantes del patrón y la forma, siendo el ADN la molécula que contiene las instrucciones para el desarrollo. El ambiente actuaría como el modelador de estas instrucciones. Asimismo, se considera que esta información existe desde antes de su uso o expresión, manteniendo la idea preformacionista. El desarrollo de los organismos es concebido como algo dado que está latente, no como un proceso de creación con múltiples factores intervinientes. Oyama (2000) plantea que los genes se conciben como «vehículos de constancia», siendo tanto el origen como el modo de transmisión de la forma o caracteres fenotípicos:

«Nuestra naturaleza es creada por un plan genético, una inteligencia dentro de los cromosomas, la cual a su vez fue creada por la Selección Natural» (Oyama, 2000, p. 12).

«El descubrimiento del ADN y la confirmación a su vez de una teoría genómica que por largo tiempo estuvo en la búsqueda de su agente material, ofrecía una aparente solución atractiva al rompecabezas del origen y la perpetuación de la forma viviente. Un objeto material alojado en cada parte del organismo, el gen, parecía cerrar la grieta entre la materia inerte y el diseño; de hecho, la infor- mación genética, por medio de su significado de in-formación en «moldear» $y$ «animar», prometía proveer las funciones cognitivas y causales necesarias para convertir un montón de sustancias químicas en un ser» (Oyama, 2000, p. 14).

Por otra parte, dentro de la filosofía griega Aristóteles distingue cuatro causas: la causa material (aquello de lo que está hecho algo), la causa formal (aquello que un objeto es), la causa eficiente (aquello que ha producido ese algo) y la causa final (aquello para lo que existe ese algo), siendo las dos primeras intrínsecas al ser (constitutivas) y las otras dos extrínsecas (explican su devenir) (Aristóteles, Metafísica, V, 2, 1013a 23 - 1014a 26). Lo molecular viene a representar esas cuatro causas. Según el paradigma actual, el gen es tanto fuente de la forma orgánica como producto de la evolución y se condice con lo que Oyama denomina función cognitiva: la causa formal (el patrón) y la causa final (la finalidad). La creencia de que la evolución actúa adaptando a los organismos a su entorno, o incluso perfeccionando funciones, es un ejemplo de la visión que se tiene acerca de la misma suministrándole un propósito a los genes. Al entender el desarrollo como un proceso madurativo, programado genéticamente, el gen también constituye la causa eficiente, logrando identificar la estabilidad con lo interno y la variabilidad con lo externo:

«El patrón suele mantenerse a pesar de considerables cambios en el genotipo, en el ambiente o en ambos [...] Cuando la variación ambiental no conduce a una variación fenotípica, el fenotipo se concluye como 'bajo control genético'. Pero cuando la variación genética no conduce a una variación fenotípica, no suele asumirse que el fenotipo típico de la especie se encuentra 'bajo control ambiental'. La convicción se mantiene en que existe una jerarquía de causas» (Oyama, 2000, p. 17).

Oyama plantea un quiebre respecto a esta concepción del papel fundamental del gen, integrándolo dentro de una red de causas: 
«La estabilidad fenotípica, así como el cambio fenotípico, debe ser explicada examinando las relaciones entre el organismo y la situación, no atribuyéndolo a uno u otro factor» (Oyama, 2000, p. 21).

«Lo que estoy discutiendo aquí es una visión de la causalidad que otorgue peso formativo a todas las influencias operativas, ya que ninguna sola es suficiente para explicar el fenómeno o cualquiera de sus propiedades, y ya que la variación en una o en muchas puede o no producir variación en el resultado, dependiendo de la configuración en el todo. [...] la selectividad recíproca de influencias, o la mutua dependencia de las causas, no sólo un conjunto entero de influencias contribuyen a un fenómeno dado, pero el efecto de cualquiera de las partes que interactúa depende tanto de sus propias cualidades como de las cualidades de las otras, normalmente en una combinación compleja» (Oyama, 2000, p. 18).

Todo lo que ocurre al organismo es por interacción de distintos elementos durante el desarrollo, la constancia de la especie a través del tiempo se logra por la interacción de los elementos del organismo con su medio, tanto interno como externo (nicho ecológico):

«A través del tiempo evolutivo, estos procesos se han vuelto más o menos confiablemente acoplados; la constancia a través de generaciones y dentro de una población se debe a estas relaciones, cuya fiabilidad es variable. No hay un vehículo de constancia [...] a menos de que el organismo y su nicho, a medida que se mueven a través del tiempo, sean así considerados. El sistema de desarrollo, sin embargo, no tiene una forma final, encriptada desde antes de su punto inicial y alcanzada en su madurez. Tiene, si uno se concentra lo suficiente, tantas formas como el tiempo tiene segmentos» (Oyama, 2000, p. 27).

\section{NUEVAS PROPUESTAS TEÓRICAS}

\section{TEORÍA EPIGENÉTICA}

El concepto de epigenética data de 1939, cuando Waddington lo define como «el estudio de todos los eventos que llevan al desenvol- vimiento del programa genético del desarrollo» (Waddington, 1939) o «el proceso de desarrollo que media entre genotipo y fenotipo» (Waddington, 1941). Actualmente se define como «el estudio de los cambios en la función de los genes que son heredables por mitosis y/o meiosis, que no entrañan una modificación en la secuencia del $A D N$ y que pueden ser reversibles.» (Holliday, 2002). Este concepto quita peso al determinismo genético, resaltando el papel de otros agentes en la expresión del genoma. La programación epigenética define el estado de expresión de los genes (estado epigenético). Éste puede ser alterado por diversas condiciones ambientales que influirán en el fenotipo de un organismo y en su comportamiento (Bedregal, Shand, Santos y Ventura-Juncá, 2010). Por ejemplo, con muy pocas excepciones, las diferencias que existen entre células especializadas son epigenéticas, no genéticas. En un organismo constituido por distintos tejidos todas las células portan la misma información genética, pero lo que determina la diferencia entre ellas es la expresión de distintas partes del genoma. No solo mantienen su fenotipo particular sino que también lo transmiten a células hijas durante la mitosis. La secuencia de pares de bases del ADN se mantiene sin cambios, pero la célula hereda caracteres adquiridos durante el desarrollo de su progenitora; la información se transmite a través de lo que se conoce como sistema de herencia epigenético (SHE) (Jablonka y Lamb, 2005).

Según varios autores (Jablonka y Lamb, 2005; Bedregal et al., 2010; Arberas y Ruggieri, 2013) existen tres mecanismos epigenéticos principales:

1) Metilación de la citosina de los pares de nucléotidos citosina-guanina ( $\mathrm{CpG}$ ) del ADN. Estos pares de bases suelen hallarse en 'islas' en la región promotora para la transcripción. Tienen tendencia a metilarse y esto evita generalmente que las secuencias génicas posteriores a las mismas se transcriban.

El proceso de metilación se produce fundamentalmente durante la mitosis celular, pudiendo ocurrir también en etapas post mitóticas (Bedregal et al., 2010). 
2) Modificación química de las histonas de la cromatina a través de la acetilación, ubiquitación o fosforilación. La cromatina puede cambiar su densidad y permitir el acceso a los genes y su expresión a través de estos procesos.

La metilación del ADN y la acetilación de las histonas son procesos que funcionan de forma coordinada y son reversibles (Bedregal et al., 2010; Arberas y Ruggieri, 2013.).

3) Micro ARNs no codificantes, denominados ARNs de interferencia, son importantes en la regulación de la activación y silenciamiento de los genes. Se producen a partir de una secuencia de ARN anormal de cadena doble que es localizada por una enzima denominada Dicer, la cual la fragmenta en pequeños ARN de interferencia (micro ARNi). Pueden silenciar cromatina, degradar ARNm o bloquear su traducción (Novina y Sharp, 2004; Castel y Martienssen, 2013).

Este sistema puede transmitirse no sólo durante la mitosis sino también a otras células y tejidos. Además de estos mecanismos, Jablonka y Lamb reconocen otras dos categorías amplias de sistemas de herencia epigenéticos (SHEs):

4) Actividad genética: se heredan, por ejemplo, circuitos de retroalimentación durante la mitosis, transfiriéndose el fenotipo celular.

5) Estructuras celulares: versiones alternativas de algunas estructuras celulares pueden heredarse debido a que las estructuras existentes guían la formación de estructuras similares en las células hijas. Ejemplo: los sistemas de membranas y los priones.

Estos sistemas no son independientes entre sí sino que se encuentran interconectados. No solo se encuentran los cinco tipos presentes en todos los organismos eucariotas unicelulares sino que también las bacterias tienen herencia epigenética. Con respecto a los organismos multicelulares, si poseen reproducción asexual, las variaciones epigenéticas pueden conducir a cambios estables que provoquen modificaciones a largo plazo.

\section{TEORÍAS DEL COMPORTAMIENTO}

El término «comportamiento» es un concepto controvertido ya que en las ciencias biológicas no se encuentra un consenso para definirlo. En este sentido Levitis, Lidicker y Freund (2009), basándose en los resultados generados a partir de una encuesta a diversos etólogos, proponen la siguiente definición: «Comportamiento es cualquier respuesta coordinada internamente (acciones o inacciones) de organismos vivos completos (individuos o grupos) a estímulos externos y/ o internos, excluyendo respuestas entendidas más fácilmente como cambios durante el desarrollo». Otros autores (Lahitte, Hurrell y Malpartida, 1993) enfatizan la necesidad de entender el comportamiento dentro del marco de la ecología, en un sentido ecopoiético: «las conductas especifican el entorno que es condición para la generación de las conductas que, a su vez, generan el entorno». De esta forma la relación organismo-entorno se expresa en el comportamiento que emerge de la misma de una forma recursiva.

Muchas veces se habla de comportamientos innatos como determinados genéticamente o encriptados en el genoma de la especie. Sin embargo, el comportamiento innato o pauta de acción fija (un conjunto de movimientos que se dan siempre de la misma forma o muy similarmente) aparece en relación con el medio, tanto interno como externo. Esto se deduce del modelo psicohidráulico planteado por Konrad Lorenz en 1970 para explicar el instinto: las pautas de acción fija responden a estímulos llave que operan sobre mecanismos desencadenantes innatos, alojados en el sistema nervioso y responsables de traducir el estímulo en una secuencia motora. Sobre los mecanismos desencadenantes innatos actúa la energía específica de acción, que es la motivación intrínseca que en cantidad suficiente produce la pauta, aún sin el estímulo (Romero, 2016). Es la relación con el medio externo y/o interno lo que determina la aparición de la conducta, no la secuencia génica compartida entre miembros de la especie. 
Las características comportamentales de un individuo están determinadas por sus genes y por el ambiente físico y social. Según diversos estudios (Bas Rodenburg, 2014), no sólo el período postnatal y el ambiente presente son de importancia, sino también el ambiente de las generaciones pasadas.

Siendo que el conjunto de marcas epigenéticas, conocido como epigenoma, sería influyente en la expresión y el silenciamiento de secuencias génicas, y dado que las variaciones comportamentales entre individuos suelen correlacionarse con variaciones en la expresión de dichas secuencias, entonces es factible que los mecanismos epigenéticos sean potencialmente capaces de afectar fenotipos tales como el comportamiento (Jablonka y Lamb 2005; Bas Rodenburg, 2014). Aunque se considera que el epigenoma actúa «orquestando» al genoma, no es la intención cambiar el foco regulatorio del desarrollo de la genética a la epigenética, sino por el contrario, integrar diversos procesos que intervienen en la generación del fenotipo. Es así que el comportamiento puede constituir un sistema de herencia propio, denominando herencia a «cualquier proceso de transmisión o adquisición mediado socialmente que resulta en la reconstrucción de un comportamiento o preferencia de un antecesor en sus descendientes».

Si bien se reserva el término 'cultura' para las poblaciones de Homo sapiens, esto surge de una visión antropocéntrica que cree que las capacidades del ser humano son únicas. Hoy en día ese paradigma se encuentra en crisis por diversas razones, entre ellas, las similitudes encontradas con otras especies animales: por ejemplo, la capacidad de fabricar y utilizar herramientas. Hay registros de cuervos de Nueva Caledonia (Corvus moneduloides) silvestres que modifican distintos materiales (ramas, plumas, pedazos de hojas, cartón) para crear herramientas que les permiten extraer larvas de troncos y árboles, y tanto primates del «nuevo mundo» (como los de la familia Cebidae) y simios del «viejo mundo» (orangutanes, gorilas y chimpancés) utilizan piedras y yunques, y modifican ramas para poder obtener diversos alimentos.
Se han encontrado variaciones en la fabricación de herramientas a escala poblacional (Boysen y Custance, 2009). Lo expuesto concuerda con la definición de cultura por Jablonka y Lamb (2009): «un sistema de patrones comportamentales, preferencias y productos de la actividad animal, transmitidos socialmente, que caracterizan a un grupo de animales sociales». El aprendizaje en los animales ocurre a través de la experiencia, que implica un cambio en el comportamiento. Si el aprendizaje es mediado socialmente, es determinante la interacción con otros individuos.

Experiencias pre-natales.- Durante el desarrollo embrionario de los mamíferos las madres transfieren factores ambientales, como recursos nutricios, a su embrión o feto por medio de la placenta (Arberas y Ruggieri, 2013). Experimentos realizados con conejos (Bilkó, Altabäcker y Hudson, 1994) han mostrado que alimentar a hembras preñadas con un alimento que encontrarían en su ambiente natural, como bayas de enebro, crea una preferencia por las mismas en las crías. Aun separando a la prole de sus madres al nacer y poniéndola con conejas no alimentadas con bayas de enebro, la preferencia se mantiene, por lo que se deduce que la información debe haber sido transmitida durante el período pre-natal. La preferencia por un alimento ingerido durante la etapa de gestación en humanas también se ha observado en sus bebés (Jablonka y Lamb, 2005).

El ambiente uterino también es permeable a las influencias hormonales de la mamífera gestante. El estrés sufrido por la madre durante el período pre-natal tiene efectos negativos sobre la regulación del eje hipotálamo-hipófisis-adrenal (HHA) del feto (Bedregal et al., 2010). El estrés se traduce en una mayor probabilidad de ocurrencia de abortos espontáneos, descendencia de menor tamaño y con mayor tendencia a enfermedades por un sistema inmune menos competente (Bas Rodenburg, 2014). Se ha observado en humanos que mujeres embarazadas con mayor ansiedad o depresión durante el tercer trimestre del embarazo tenían 
bebés que mostraban una mayor respuesta al estrés mediada por cortisol a los tres meses de edad (Oberlander et al., 2008).

Más allá de los mamíferos, las aves han sido utilizadas como un modelo importante debido a que la composición del huevo no cambia una vez puesto. Experimentos llevados a cabo con gallinas ponedoras a las cuales se las estresó durante el período de puesta (determinando a través del análisis del nivel de corticoesterona en fecas) tuvieron polluelos más temerosos y menos competitivos que los polluelos del grupo control (Janczak, Torjesen, Palme y Bakken, 2007). Cuando se trató los huevos con corticoesterona se obtuvieron efectos similares, indicando que las hormonas del estrés juegan un papel fundamental en este proceso (Freire, van Dort y Rogers, 2006).

Experiencias post-natales. - La lactancia en mamíferos constituye una etapa en la cual se siguen transmitiendo recursos nutricios a la progenie. En este sentido, los experimentos con conejos también mostraron una preferencia manifiesta por las bayas de enebro en crías cuyas madres no habían sido alimentadas con bayas de enebro pero que al nacer fueron puestas a mamar de madres que sí las habían ingerido (Bilkó et al., 1994). Esta tendencia también se observa en humanos y en otros experimentos con ratas (Jablonka y Lamb, 2005), por lo que se cree que la lactancia es una fuente de información que genera una preferencia evidenciada en el comportamiento. En ratas, esta información además puede transmitirse a través del aliento y la saliva durante el acicalamiento, y a través de las heces (coprofagia, especialmente importante en muchos animales herbívoros ya que así transmiten las bacterias necesarias para la digestión de la celulosa).

Un ejemplo muy citado sobre experimentos que muestran modificaciones epigenéticas como resultado de experiencias específicas es aquel realizado por Liu et al. (1997), en el cual investigaron las consecuencias a largo plazo de distintos tipos de cuidado maternal temprano en ratas. En las ratas madres se observó que había diferencias comportamentales respecto al cuidado de la progenie: algunas pasaban mayor tiempo amamantando y acicalando a sus crías que otras. Los resultados mostraron que las crías de las madres más cuidadosas mostraban mayor resiliencia frente a eventos estresantes y esto estaba mediado por un patrón de expresión génica modificado involucrado en el sistema de respuesta al estrés, como también en los genes que gobernaban el desarrollo sináptico del hipocampo. Un experimento posterior mostró un patrón de metilación distintivo en el hipocampo de las crías en función de si habían recibido mayores o menores cuidados postnatales, y asociado también con alteraciones en la acetilación de histonas y con la unión del factor de transcripción NGFI-A con el gen codificante para el receptor de glucocorticoides NR3C1 (Bas Rodenburg, 2014). De igual modo, mediante la transferencia de camadas entre dos madres con patrones conductuales distintos, confirmaron que la respuesta al estrés es dependiente de la crianza y no del background genético (Bedregal et al., 2010). Este experimento demostró que distintos patrones conductuales maternos durante la primera etapa de vida tienen una influencia en la expresión génica en el cerebro de las crías, que se manifiesta en comportamientos distintos. El estilo de crianza recibido era heredado y se manifestaba a su vez cuando las crías se convertían en madres.

La experiencia de los individuos durante su vida puede llevarlos a desarrollar distintos comportamientos. La complejidad de los mismos dependerá del nivel cognitivo de la especie, del individuo en particular (también afectado por las experiencias pre-natales y el primer período post-natal) y se desarrollará según sus interacciones sociales y los problemas que tenga que enfrentar en su entorno. Existe evidencia de que el aprendizaje social, aunque sea en su forma más simple, se encuentra bien establecido en peces, aves y mamíferos (Laland y Hoppitt, 2003; Boysen y Custance, 2009; Brown, 2015). La transmisión social puede llevar a que un comportamiento aprendido por un individuo 
se transmita al resto de su comunidad y se constituya en herencia comportamental.

Existen estudios a largo plazo que dan cuenta de que hay una enorme diversidad de tradiciones animales, que involucran distintas especies y aspectos de la vida. Hasta 1999, y como parte de los resultados de estudios de más de 151 años de observación de chimpancés, se contabilizaban hasta treinta y nueve patrones comportamentales distintos (incluyendo uso de herramientas, acicalamiento y comportamiento de cortejo) habituales en algunas comunidades pero ausentes en otras, descontando explicaciones ecológicas (Whiten et al., 1999). Esto sugiere variación cultural, siendo cada comunidad de chimpancés distintiva en su repertorio comportamental, algo característico de las culturas humanas que no había sido previamente reconocido para especies no humanas (Whiten et al., 1999). También se ha observado una variación comportamental según variación geográfica en orangutanes, encontrando correlaciones entre distancia geográfica y diferencias culturales, entre la abundancia de oportunidades para el aprendizaje social y el tamaño del repertorio cultural local, y sin efectos del hábitat en el contenido cultural (van Schaik et al., 2003). Otro trabajo posterior (Krützen, Willems y van Shaik, 2011) encontró que la variación genética explicaba muy poco de las diferencias comportamentales entre las poblaciones, mientras que las diferencias ambientales tenían mayor influencia, resaltando la importancia de la plasticidad en el desarrollo. Ésta podría ser clave para la supervivencia de poblaciones de animales longevos con una tasa de reproducción baja.

\section{TEORÍA DE CONSTRUCCIÓN DE NICHO}

Es necesario mencionar la Teoría de Construcción de Nicho (TCN) (Odling-Smee, 1996; Scott-Phillips et al., 2014) como una forma de abordar las interacciones entre los individuos y su ambiente en relación a la herencia epigenética y comportamental. La construcción de nicho es el proceso por el cual los organismos producen cambios en su entorno y/o el de otros individuos, de su misma especie o de otra, a través de su metabolismo, sus actividades y sus decisiones, pudiendo tener consecuencias ecológicas y evolutivas importantes. Lejos de entender al individuo como 'seleccionado' por el ambiente en la 'lucha por la supervivencia', esta teoría reconoce que los individuos, tanto a nivel individual como poblacional y comunidad, co-construyen su entorno y co-evolucionan con él (Odling-Smee, 1996; Laland et al., 2014). Esto genera redes de interrelaciones, fenómenos de mutualismo, parasitismo, comensalismo, etc. que son producto de la interacción misma y no adaptaciones. La TCN tampoco considera que los cambios producidos por los organismos en su entorno sean necesariamente adaptativos, sino que constituyen un flujo de materia y energía: los aportes químicos de la materia cadavérica al suelo, el dióxido de carbono liberado a la atmósfera producto del metabolismo de las plantas, la capa de aire caliente que rodea a los vertebrados homeotermos, todo eso es construcción de nicho. La TCN reconoce asimismo un concepto ampliado de herencia, que incluye la «herencia ecológica»: el ambiente modificado por un organismo es heredado a su descendencia. Esto puede incluir tanto lo material (por ejemplo, una represa de castores o el legado monetario en las sociedades humanas capitalistas) como lo comportamental (tradiciones, cultura).

\section{IMPLICANCIAS SOBRE HERENCIA, ADAPTACIÓN Y EVOLUCIÓN}

Desde el advenimiento de la teoría de la evolución y su fusión con la genética, ha sido ampliamente aceptada como una verdad que la información sólo puede fluir en la dirección del ADN al fenotipo y nunca en la dirección contraria. En otras palabras, ningún carácter adquirido durante la vida como resultado de eventos ambientales sería capaz de afectar la estructura o función del ADN. Por lo tanto, de acuerdo con esta visión establecida, las variaciones adquiridas en el fenotipo, como el comportamiento o 
la epigenética, no podrían transmitirse a la descendencia (Jensen, 2013). Sin embargo, hemos visto que el desarrollo fenotípico del individuo es influenciado por aspectos no genéticos tales como el ambiente uterino o las experiencias posteriores, especialmente durante la primera etapa de vida. Cabe mencionar, si bien no ha sido el foco de esta revisión, que factores tales como la alimentación (incluida la malnutrición) y la exposición a sustancias tóxicas también tienen efectos a largo plazo sobre el fenotipo, pudiendo llegar a ser estos efectos transgeneracionales como lo evidencian los estudios sobre la hambruna holandesa del invierno de 1944 (Roseboom, de Rooji y Painter, 2006; Painter et al., 2008). Estos estudios han mostrado una tendencia al desarrollo de distintas enfermedades cardiovasculares, renales, pulmonares, aumento de colesterol o diabetes en los nietos e hijos de mujeres embarazadas durante el año que la ciudad de Ámsterdam estuvo sitiada por los nazis según el momento de la gestación en el cual ellas pasaron hambre. Estos autores consideran que los cambios fenotípicos ocurren a partir del cambio en la expresión de las secuencias génicas, no a partir del cambio en las bases nucleotídicas de las mismas. Pero para poder considerar a la epigenética y al comportamiento como motores del cambio evolutivo, es necesario que la variación sea heredable.

Aquí se propone que la llamada «herencia suave» (es decir, los caracteres adquiridos) es factible de ser transferida a la descendencia e intervenir en la diversificación y generación de nuevas especies. La definición tradicional de evolución (el cambio en la composición genética de las poblaciones a través de generaciones sucesivas), por tanto, debería modificarse. Para Oyama, la herencia debería definirse como «la transmisión de las condiciones para el desarrollo, de cualquier manera» resaltando que «esto no requiere ninguna distinción entre caracteres innatos y adquiridos [...] sino algún grado de asociación de las influencias del desarrollo» (Oyama 2000, p. 43).

La transmisión de caracteres a través de la epigénesis ha sido un prerrequisito para la evolución de la complejidad de las formas de vida. Sin herencia epigenética durante el desarrollo, no podría haber una diferenciación celular estable que permitiera la formación de tejidos, su mantenimiento y la división de funciones entre los mismos (Jablonka y Lamb, 2005). Según estas autoras, las marcas epigenéticas heredables pueden influenciar la aparición de variantes alélicas. También la acumulación de variación epigenética puede conducir finalmente a la expresión o el silenciamiento de secuencias génicas que sí tengan efectos fenotípicos (Belyaev, Ruvinsky y Trut, 1981). Debido a que, como hemos visto, las marcas epigenéticas son influenciadas por el ambiente, se considera que el mismo juega un rol no sólo como agente de selección, sino también como agente de variación. En este sentido, Dressino (2010) hace referencia a que esto genera un quiebre conceptual respecto a la dominancia exclusiva del mecanismo de selección como agente depurador de variantes, pasando a ser un agente generador de variación. Los cambios epigenéticos pueden dar lugar a procesos de especiación: al estar vinculados principalmente con el transcriptoma (el conjunto de moléculas de ARN obtenido a partir de la transcripción del $\mathrm{ADN}$ ) y no con los genes, la selección natural no tiene influencia a este nivel de complejidad.

Por otro lado, los efectos maternos pueden auto-perpetuarse y mantenerse durante varias generaciones, creando un «momentum evolutivo» que persiste por mucho tiempo después de que desaparece el estímulo ambiental que generó el efecto maternal en un primer momento (Pfenning y Servedio, 2013). La inmunidad adquirida a patógenos, las hormonas del estrés, las sustancias tóxicas, pueden transmitirse a través de la placenta de la madre a su progenie y también a través de la lactancia. En el caso de los cuidados maternales, el fenotipo comportamental se reproduce en las sucesivas generaciones.

En base a esto, Pfenning y Servedio (2013) proponen la definición del término evolución como «cualquier cambio heredado en las características de un grupo de organis- 
mos durante generaciones, incluyendo entonces la posibilidad de que la herencia de caracteres fenotípicos pueda ocurrir a través de otros procesos más allá de aquellos que involucran cambios en la secuencia de $A D N$ ».

Whiten y van Schaik (2007) hacen una revisión sobre la evolución de la cultura e inteligencia animal y concluyen que: «las correlaciones inter- e intraespecíficas identificadas entre la complejidad cultural, las capacidades de aprendizaje social, las oportunidades de aprendizaje social y la encefalización sugieren un proceso de evolución en espiral en el cual el aprendizaje social puede engendrar tradiciones, la emergencia de múltiples tradiciones selecciona una capacidad de aprendizaje social mayor, múltiples tradiciones generan individuos más inteligentes, individuos más inteligentes innovan y aprenden mejor y a esto se asocia la selección para la encefalización; además, la retroalimentación positiva se espera entre muchos de estos efectos». Estos autores hacen una diferencia entre tradiciones animales y cultura animal: si bien ambas están mediadas por el aprendizaje social para su enseñanza y mantenimiento a través del tiempo, la cultura implica múltiples tradiciones más complejas.

Jablonka y Lamb (2005) proponen un orden jerárquico en la evolución, en el cual los sistemas de herencia epigenéticos permitieron la evolución de organismos multicelulares, con células diferenciadas en tejidos cumpliendo distintas funciones. Tanto la epigenética como la genética continuaron cumpliendo un papel protagónico en la evolución de organismos unicelulares, plantas, hongos y animales simples. Con la evolución de animales más complejos con sistema nervioso central se hizo posible la transmisión del comportamiento, teniendo un potencial adaptativo distinto a las mutaciones genéticas o la herencia epigenética. En algunos animales esto llevó a la creación de tradiciones y culturas, a través de comportamientos socialmente aprendidos en una estructura social más compleja. Eventualmente, en nuestro linaje emergió la comunicación simbólica, un nuevo nivel de herencia, por el momento, exclusivo en nuestra especie.
Todo esto lleva también a la revisión del término adaptación. Los organismos ya no serían agentes pasivos frente al ambiente y no habría secuencias génicas aptas o no aptas juzgadas impasiblemente por éste a través de la selección natural. Durante el transcurso de la vida en la Tierra, las novedades evolutivas no aparecieron necesariamente para cumplir la función que ahora vemos. Caracteres fenotípicos que antiguamente se consideraban adaptaciones al medio hoy han perdido ese estatus ontológico: un ejemplo es la reducción de miembros de los ofidios, entendidos a través de la evidencia actual como producto de la expansión del dominio de los genes Hox durante el desarrollo (Cohn y Tickle, 1999). Otras propuestas teóricas (Dressino, Denegri y Lamas, 2004) abordan la necesidad de entender el fenómeno adaptativo de una manera más amplia: algunos caracteres cumplen más de una función (por ejemplo, el pelo de los mamíferos tiene función aislante, sensitiva, en el cortejo, como camuflaje), por lo cual una visión más integrada y menos fragmentada parece necesaria para la comprensión del fenómeno evolutivo.

\section{APORTES A LA TEORÍA DE LOS SISTEMAS DE DESARROLLO}

El concepto de epigenética y la investigación asociada a ésta han instalado un paradigma nuevo que supera la dicotomía genética y ambiente a favor de modelos de desarrollo más holísticos, bioecológicos (Brofenbrenner, 1979). La TCN constituye un abordaje teórico de estas características y resulta congruente con la propuesta de Oyama: en síntesis, el entendimiento del desarrollo como un sistema dinámico en el cual el proceso construye al individuo a la vez que al entorno (tanto físico como social) a partir de la retroalimentación entre las partes y no como un proceso pre-programado y determinado genéticamente. De esta forma, el mantenimiento de las características constitutivas de los individuos se concibe a partir de, por un lado, los procesos epigenéticos de diferenciación y mantenimiento celular. 
Y, por otro, a partir de la canalización del desarrollo, esto es, que cambios ambientales o mutaciones no tengan necesariamente efectos fenotípicos. Además, considera otras formas de herencia (ecológica, epigenética, comportamental) con influencia en los procesos evolutivos.

\section{CONCLUSIONES}

La biología teórica y la filosofía de la biología no son áreas a las que se les otorgue la importancia necesaria dentro del ámbito científico-académico. Los temas tratados en este artículo parten de supuestos que la mayoría de las veces no son cuestionados: «Estos temas conceptuales [...] son comúnmente desconsiderados por los científicos como mera filosofía, no ciencia (y ni siquiera teoría, porque no generan hipótesis específicas), pero, si qué constituye los datos y si lo que esos datos significan no son una preocupación legítima de la ciencia, ¿entonces qué son?» (Oyama, 2000, p. 94).

En base a lo expuesto, resulta necesario redefinir conceptos básicos: evolución, herencia, adaptación. Esta tarea implica también una rearticulación con las teorías dominantes que los contienen. Al perder poder explicativo sus términos fundamentales tal como fueron definidos en el pasado, la estructura lógica del paradigma se pone en tela de juicio. Quizás sea hora de revisar el papel central del gen en la Teoría Sintética de la Evolución.

El problema en visualizar el comportamiento como un sistema de herencia auténtico y como motor evolutivo reside en que no abunda información sobre las tradiciones animales por no ser un área de investigación preponderante dentro de la biología. Es necesario tener en cuenta los aspectos no científicos de esta razón: hablamos de estudios más complejos (deben llevarse a cabo en el campo y se requiere entrenamiento en la metodología de observación de comportamiento) y a largo plazo, para los cuales es más difícil conseguir subsidios que para estudios a corto plazo (Jablonka y Lamb, 2005). Además, existe la resistencia antropocéntrica a aceptar las semejanzas del ser humano con otras especies. Muchas veces esto genera un sesgo en las investigaciones que lleva más a buscar responder preguntas sobre lo que los animales no pueden hacer que sobre lo que los animales sí pueden hacer y esto parte de supuestos, diseños experimentales y metodología errónea.

\section{AGRADECIMIENTOS}

Agradezco a la Dra. Lamas y al Dr. Dressino (Universidad Nacional de La Plata), sin cuya guía e inspiración no habría sido posible dar mis primeros pasos en la investigación de la biología teórica.

A la Dra. Lamas, al Lic. Nicanoff, revisores anónimos, y al editor de la revista por las valiosas correcciones que permitieron mejorar el manuscrito.

\section{FINANCIAMIENTO}

Este trabajo fue realizado en el marco de una pasantía dentro del proyecto de Incentivos $N^{\circ} 775$, La teoría de los Sistemas de Desarrollo: aspectos teóricos-epistemológicos y sus implicancias evolutivas financiado por la Facultad de Ciencias Naturales y Museo de la Universidad Nacional de La Plata.

\section{PARTICIPACIÓN}

La autora ha realizado la totalidad del trabajo expuesto, con las sugerencias de la Dra. Susana Gisela Lamas y la Lic. Nair Nicanoff.

\section{CONFLICTO DE INTERESES}

La autora declara no tener conflictos de intereses con terceros.

\section{LITERATURA CITADA}

Arberas, C., Ruggieri, V. (2013). Autismo y epigenética. Un modelo de explicación para la comprensión de la génesis en el trastorno del espectro autismo. MEDICINA (Buenos Aires), 73, 20-29.

Bas Rodenburg, T. (2014). The role of genes, epigenetics and ontogeny in behavioural development. Applied Animal Behaviour Science, 157, 8-13. 
Bedregal, P., Shand, B., Santos, M. J., Ventura-Juncá, P. (2010). Aportes de la epigenética en la comprensión del desarrollo del ser humano. Revista Médica de Chile, 138, 366-372.

Belyaev, D. K., Ruvinsky, A. O., Trut, L. N. (1981). Inherited activation-inactivation of the star gene in foxes: its bearing on the problem of domestication. The Journal Of Heredity, 72, 267-74.

Bilkó, A., Altabäcker, V., Hudson, R. (1994). Transmission of food preference in the rabbit: The means of information transfer. Physiology \& Behavior, 56, 907912 .

Boysen, S., Custance, D. (2009). The Smartest Animals on the Planet: Extraordinary Tales of the Natural World's Cleverest Creatures. Canada: Firefly Books Ltd.

Brofenbrenner, U. (1979). The ecology of human development. Cambridge: Harvard University Press.

Brown, C. (2015). Fish intelligence, sentience and ethics. Animal Cognition, 18, 117.

Calvo Martínez, T. (1994). Libro V, Capítulo 2. En Aristóteles: Metafísica. [207211). Madrid: Gredos.

Castel, S. E., Martienssen, R. A. (2013). RNA interference in the nucleus: roles for small RNAs in transcription, epigenetics and beyond. Nature Reviews Genetics, 14, 100-112.

Cohn, M. J., Tickle, C. (1999). Developmental basis of limblessness and axial patterning in snakes. Nature, 399, 474-479.

Dressino, V. (2010). La encrucijada de la teoría sintética: expansionismo o nueva síntesis teórica. Revista Argentina de Antropología Biológica, 12, 15-25.

Dressino, V., Denegri, G. M., Lamas, S. G. [2004). Alcances y limitaciones de la definición de adaptación aplicada al fenómeno del parasitismo: una propuesta teórica. Episteme (Porto Alegre), 19, 69-80.

Dobzhansky, T., Ayala, F. J., Stebbins, G.L., Valentine, J.W. (1977). Evolution. San Francisco: W.H. Freeman.

Freire, R., van Dort, S., Rogers, L. J. (2006). Pre- and post-hatching effects of corticosterone treatment on behavior of the domestic chick. Hormones and Behaviur. 49, 157-165.

Holliday, R. (2002). Epigenetics comes of age in the twenty first century. Journal of Genetics, 81, 1-4.

Jablonka, E. y Lamb. M. J. (2005). Evolution in Four Dimensions: Genetic, Epigenetic, Behavioral, and Symbolic Variation in the History of Life. London: The MIT Press.

Janczak, A. M., Torjesen, P., Palme, R., Bakken, M. [2007). Effects of stress in hens on the behaviour of their offspring. Applied Animal Behaviour Science, 107, 66-77.

Jensen, P. (2013). Transgenerational epigenetic effects on animal behavior. Progress in Biophysics and Molecular Biology, 113, 447-454.

Krützen, M., Willems, E. P., van Shaik C. P. [2011]. Culture and geographic variation in orangutan behavior. Current Biology, 21, 1808-1812

Lahitte, H.B., Hurrell, J., Malpartida, A. (1993). Ecología de la conducta. De la información a la acción. Buenos Aires: Ediciones Nuevo Siglo.

Laland, K. N., Hoppitt, W. J. E. (2003). Do animals have culture?. Evolutionary Anthropology, 12, 150-159.

Laland, K., Uller, T., Feldman, M., Sterelny, K., Müller, G. B., Moczek, A., Jablonka, E., Odling-Smee, J., Wray, G. A., Hoekstra, H. E. , Futuyma, D. J. , Lenski, R. E., Mackay, T. F. C. , Schluter, D., Strassmann J. E. (2014) Does evolutionary theory need a rethink?. Nature, 514, 161-164.

Levitis, D. A., Lidicker, W. Z., Freund, G. [2009]. Behavioural biologists don't agree on what constitutes behaviour. Animal Behaviour, 78, 103-110.

Liu, D., Diorio, J., Tannenbaum, B., Caldji, C., Francis, D., Freedman, A., Sharma, S., Pearson, D., Plotsky, P. M., Meanley, M. J. (1997). Maternal care, hippocampal glucocorticoid receptors, and hypothalamic-pituitary-adrenal responses to stress. Science, 277, 1659-1662.

Novina, C. D., Sharp, P. A. (2004). The RNAi revolution. Nature, 430, 161-164.

Oberlander, T. F., Weinberg, J, Papsdorf, M., Grunau, R., Misri, S., Devlin, A. M. [2008). Prenatal exposure to maternal depression, neonatal methylation of human glucocorticoid receptor gene [NR3C1) and infant cortisol stress responses. Epigenetics, 3, 97-106.

Odling-Smee, F.J. (1996). Niche construction, genetic evolution and cultural change. Behavioural Processes, 35, 195-205.

Oyama, S. (2000). The ontogeny of information: Developmental Systems and Evolution. USA: Duke University Press.

Painter, R.C., Osmond, C., Gluckman, P., Hanson, M., Philips, D.l., Roseboom, T.J. [2008). Transgenerational effects of prenatal exposure to the Dutch famine 
on neonatal adiposity and health in later life. BJOG: An International Journal of Obstetrics \& Gynaecology, 115, 12431249.

Pfenning, D. W., Servedio, M. R. (2013). The role of transgenerational epigenetic inheritance in diversification and speciation. Non-genetic Inheritance, 1, 17-26.

Romero, C. A. Modelo Psicohidráulico de Instinto (Konrad Zacarias Lorenz): Una Aproximación desde la Física de Fluidos, Academia. Mayo, (2016). http://www.academia.edu/8736528/ Modelo_Psicohidr\%C3\%A1 ulico_de_ Instinto_Konrad_Zacarias_Lorenz_ Una_Aproximaci\%С3\%B3n_desde_la_ F\%C3\%ADsica_de_Fluidos

Roseboom, T., de Rooij, S., Painter, R. [2006]. The Dutch famine and its longterm consequences for adult health. Early Human Development, 82, 485491.

Scott-Phillips, T. C., Laland, K. N., Shuker, D. M., Dickins, T. E., West, S. A. (2014). The niche construction perspective: a critical appraisal. Evolution, 68, 12311243.

van Schaik, C.P., Ancrenaz, M., Borgen, G., Galdikas, B., Knott, C. D., Singleton, I, Suzuki, A., Utami, S. S., Merrill, M. [2003). Orangutan cultures and the evolution of material culture. Science, 299, 102-105.

Waddington, H. (1939). Development as an epigenetic process. En: An Introduction to Modern Genetics (154-156). London: G. Allen and Unwin Itd.

Waddington, H. (1941). The pupal contraction as an epigenetic crisis in Drosophila. Proceedings of the Zoological Society of London, 111, 181-188.

Whiten, A., Goodall, J., McGrew, W.C., Nishida, T., Reynolds, V., Sugiyama, Y., Tutin, C. E., Wrangham, R. W., Boesch, C. (1999). Cultures in chimpanzees. Nature, 399, 682-685.

Whiten, A., van Schaik, C. P. (2007). The evolution of animal 'cultures' and social intelligence. Philosophical Transactions Royal Society B, 362, 603-620. 